\title{
Removal Characteristics of Tanic Acid Adsorbed on MIEX Resin
}

\author{
Lei Ding*, Yunhua Zhu, Bin Du, Jiangya Ma, Xinxi Zhang \\ School of Civil Engineering and Architecture, Anhui University of Technology, \\ 59 Hudong Road, Maanshan 243002, P.R. China
}

Received: 5 June 2016

Accepted: 26 September 2016

\begin{abstract}
This study evaluated the removal characteristics of tanic acid (TA) adsorbed on MIEX resin by batch experiments. MIEX resin can effectively remove TA from raw water at $\mathrm{pH}$ 6-9. Chloride and sulfate have adverse effect on the removal of TA. Conversely, bicarbonate can further the removal of TA. The Elovich model is the most suitable for depicting the kinetic process, and liquid film diffusion dominates the adsorption rate. The Freundlich model is reliable for describing the adsorption equilibrium. Adsorption is an endothermic, entropy-driving, and thermodynamically spontaneous process. The energy changes confirm the physical adsorption and dominate adsorption behavior. The sodium chloride solution $(0.5 \%)$ can effectively regenerate the MIEX resin saturated TA, and the regenerated resin can be used circularly. Therefore, MIEX resin is a promising adsorbent for the removal of TA from raw water.
\end{abstract}

Keywords: MIEX resin, tannic acid, equilibrium, kinetics, thermodynamics

\section{Introduction}

Tannic acid (TA) is a component of natural organic matter (NOM) and is ubiquitously present in most surface and groundwater due to the decomposition of plant biomass [1-2]. Previous research has demonstrated that TA is toxic for aquatic organisms such as algae, phytoplankton, fish, and invertebrates, which can cause serious environment problems [3]. Particularly, TA can react with chlorine and form carcinogenic disinfection by-products (DBPs) during the conventional chlorination disinfection process of drinking water [4-5]. Therefore, it is necessary to seek effective methods for reducing and removing TA from raw water.
A variety of alternative technologies have been developed to remove TA from aqueous solutions, such as chemical oxidation [6], electrochemical process [7], coagulation [8], biological process [9], membrane [1011], and adsorption processes [12]. Among these methods, adsorption has been extensively utilized because of its simplicity and high efficiency. Many adsorbents, such as amino-functionalized magnetic nanoadsorbent [13], chitosan [14], surfactant-modified zeolite [2], resin [3], silica [15], and activated carbon [12, 16] have been utilized to remove TA from water and wastewater. Among different adsorbents, the anion ion-exchange resin is considered one of the most effective methods due to its high removal efficiency [17]. As a novel anion ionexchange resin, magnetic ion exchange (MIEX) resin can be a potential candidate for TA removal with its promising technology for NOM removal from drinking water [18].

*e-mail: dinglei1978@163.com 
MIEX resin, prepared by Orica, is a macroporus, strong-base, anion exchange resin with quaternary amine groups and chloride as the exchangeable ion [19]. It has two particular advantages compared with traditional ion-exchange resin: its smaller size and magnetism [20]. The average diameter of MIEX resin particles is approximately $180 \mu \mathrm{m}-2-5$ times smaller than that of traditional ion exchange resin, which makes resin particle possess much greater external surface area and a more rapid adsorptive rate [21]. Owing to the smaller resin particles, MIEX resin can be used in a completely mixed reactor by mechanical mixing with low stirring intensity. This compensates high capital costs and limited flux in a fixed-bed column typically filled with conventional resin [22]. In addition, iron oxide $\left(\gamma-\mathrm{Fe}_{2} \mathrm{O}_{3}\right)$ is integrated into the polyacrylic matrix during the preparation of MIEX resin, which makes resin particles possess magnetism [23]. The magnetic property of MIEX resins makes them easy to separate from water after adsorption, even though they are very small. Based on these advantages, MIEX resin has been utilized to remove different pollutants from raw water, such as NOM [21, 24], inorganic anion ions [25-27], and micro-pollutants [23, 28]. With relation to the removal of NOM from raw water using MIEX resin, previous research has demonstrated that removal efficacy was usually described by some comprehensive parameters of organic matter, such as DOC and $\mathrm{UV}_{254}$ [24]. T. Bond et al. found that MIEX resin with a dosage of $10 \mathrm{~mL} / \mathrm{L}$ can remove 56-92\% TA from water [29]. However, the related information about adsorption equilibrium, kinetics, thermodynamics, and desorption of TA onto MIEX resin is lacking. Nevertheless, these characteristics are useful for optimizing the parameters for the removal of TA by MIEX resin. Also, they are crucial for better understanding the removal process of TA using MIEX resin.

Accordingly, the objective of this study was to systematically evaluate the removal characteristics of TA adsorbed on MIEX resin so as to provide theoretical and technical support for the TA removal from raw water using MIEX resin. Firstly, adsorption kinetics and the diffusion mechanism of TA adsorbed on MIEX resin at different initial concentrations was performed. Secondly, the equilibrium adsorption performances at three different temperatures and the thermodynamic characteristics of the adsorption process were explored. Thirdly, the impact of factors such as $\mathrm{pH}$ and coexisting anions on the removal of TA were studied. Desorption was also conducted in order to evaluate the recyclability of MIEX resin.

\section{Materials and Methods}

Materials

Adsorbent

MIEX resin was supplied by the Beijing Sino-Australia Orica Watercare Technology \& Equipment Co., Ltd. Before use, the virgin MIEX resin was rinsed repeatedly to wash away the impurities and stored as slurry in Millipore ultrapure water at room temperature $\left(20^{\circ} \mathrm{C}\right)$. Then a suitable volume of resin used in every adsorption experiment was taken out after being still-settled for $30 \mathrm{~min}$.

\section{Chemicals and Adsorbate}

All chemicals used in this study were analytical reagent (AR) grade, and purchased from Sinopharm Chemical Reagent Co., Ltd., China. TA was the adsorbate in this study. The precise stock solution of TA $(1000 \mathrm{mg} / \mathrm{L})$ was prepared by dissolving the appropriate amount of TA in ultra-pure water. Tested samples used in adsorption experiments were achieved by diluting standard stock solution with distilled water where needed.

\section{Methods}

\section{Kinetic Studies}

The kinetic studies were conducted by batch experiments. A volume of $0.25 \mathrm{~mL}$ MIEX resin was added into a set of $800 \mathrm{~mL}$ beakers containing $500 \mathrm{~mL}$ of TA solution with varying initial TA concentrations $(10,20,30 \mathrm{mg} / \mathrm{L})$, and then these solutions were stirred on a series of digital display stable temperature magnetic stirrers $(78 \mathrm{HW}-1)$ at $15^{\circ} \mathrm{C}$. Then, at different predetermined time intervals $(0,5,15,30,50,80,120$, and $160 \mathrm{~min}$ ), the content was filtered and the supernatant was analyzed for the residual TA concentration using a Shimadzu UV/Vis Spectrophotometer (model UV-3600, Japan). All the adsorption experiments were carried out in triplicate and the average values were reported.

The amount of TA adsorbed onto MIEX resin at time $\mathrm{t}, \mathrm{q}_{\mathrm{t}}(\mathrm{mg} / \mathrm{mL})$ was calculated by the following equation:

$$
q_{t}=\frac{\left(C_{0}-C_{t}\right) V}{W}
$$

...where $\mathrm{C}_{0}$ and $\mathrm{C}_{\mathrm{t}}$ are the liquid-phase concentrations of TA at initial and time $t(\mathrm{mg} / \mathrm{L}), \mathrm{V}$ is the solution volume $(\mathrm{L})$, and $\mathrm{W}$ is the volume of adsorbent $(\mathrm{mL})$.

In order to recognize the kinetic model of TA adsorbed onto MIEX resin, the kinetics data of TA adsorbed on MIEX resin were analyzed and simulated by the pseudo first-order, pseudo second-order, and Elovich kinetic models. The equations of kinetics models above are given as follows [26-27, 30]:

Pseudo first-order model:

$$
q_{t}=q_{e}\left(1+e^{-k_{1} t}\right)
$$

Pseudo second-order model:

$$
q_{t}=\frac{k_{2} q_{e}{ }^{2} t}{1+k_{2} q_{e} t}
$$


Elovich model:

$$
q_{t}=\frac{1}{\beta} \ln (1+\alpha \beta t)
$$

... where $\mathrm{q}_{\mathrm{e}}$ is the equilibrium adsorption capacity $(\mathrm{mg} / \mathrm{L})$, $\mathrm{k}_{1}$ and $\mathrm{k}_{2}$ are the kinetic constants for the pseudo first-order and the pseudo second-order $\left(\mathrm{min}^{-1}, \mathrm{~mL} / \mathrm{mg} \min \right), \alpha$ is the initial adsorption rate $(\mathrm{mg} / \mathrm{mL} \mathrm{min})$, and $\beta$ is the sorption constant ( $\mathrm{mL} / \mathrm{mg})$.

During a solid-liquid adsorption system, the removal process of adsorbate adsorbed from liquid-to-solid phase usually involves three consecutive steps [31]: 1) transfer of the adsorbate molecules or ions from the bulk solution to the solid surface, also film diffusion; 2) transfer of adsorbate molecules or ions into the interior pores of the adsorbent, i.e., intra-particle diffusion; and 3) adsorption reaction at the active sites. Among these three steps, the third step is not assumed to be the rate-determining step because it is usually very fast [32]. Thus, film or/and intraparticle diffusion actually control the whole adsorption rate. In order to better understand the adsorption kinetic process, the intra-particle and Boyd models were used to further determine the diffusion mechanism of the adsorption process. And the equations are expressed as follows [12, 27]:

Intra-particle model:

$$
q_{t}=k_{i d} t^{\frac{1}{2}}+C_{i} q_{i}
$$

Boyd model:

$$
\begin{gathered}
F=1-\frac{6}{\pi^{2}} \sum_{n-1}^{\infty} \frac{1}{n^{2}} \mathrm{e}^{-n^{2} B t} \\
F=\frac{q_{t}}{q_{\max }} \\
B t=-0.4977-\ln \left(1-\frac{q_{t}}{q_{e}}\right)
\end{gathered}
$$

...where $\mathrm{k}_{\text {id }}$ is the rate constant of the intra-particle diffusion model, $\mathrm{F}$ is the fractional attainment of equilibrium at time $t, B$ is time constant, and $\mathrm{q}_{\max }$ is the theoretical maximum equilibrium capacity $(\mathrm{mg} / \mathrm{mL})$.

\section{Adsorption Equilibrium Studies}

The static equilibrium experiments were performed at different temperatures $\left(20,30\right.$, and $\left.40^{\circ} \mathrm{C}\right)$. A volume of $0.25 \mathrm{~mL}$ MIEX resin was added into $500 \mathrm{~mL}$ of a series of TA solutions with the various concentrations (1, $2,3,4,5,6,7,8,9$, and $10 \mathrm{mg} / \mathrm{L})$ in $800 \mathrm{~mL}$ beakers. These solutions were then agitated at a constant speed of $150 \mathrm{rpm}$ for $150 \mathrm{~min}$. After adsorption, the samples were separated by filtration and the TA concentrations in filtrate were determined. The equilibrium adsorption capacity, $\mathrm{q}_{\mathrm{e}}$ $(\mathrm{mg} / \mathrm{mL})$, was calculated using the following equation:

$$
q_{e}=\frac{\left(C_{0}-C_{e}\right) V}{W}
$$

...where $\mathrm{C}_{\mathrm{e}}$ is the liquid-phase concentration of TA at equilibrium $(\mathrm{mg} / \mathrm{L})$.

In order to find an appropriate model to describe equilibrium performance of TA adsorbed on MIEX resin, the Langmuir and Freundlich isotherm models were applied to analyze the equilibrium data. And the models were described as [27, 33]:

Langmuir isotherm:

$$
q_{e}=\frac{q_{\max } b C_{e}}{1+b C_{e}}
$$

Freundlich isotherm:

$$
q_{e}=k_{f} C_{e}^{\frac{1}{n}}
$$

...where $\mathrm{b}$ is a Langmuir isotherm adsorption constant $(\mathrm{L} / \mathrm{mg})$ and $\mathrm{k}_{\mathrm{f}}$ and $\mathrm{n}$ are the indicators of the adsorption capacity and adsorption intensity $\left(\mathrm{mg} / \mathrm{mL},(\mathrm{L} / \mathrm{mg})^{1 / n}\right)$.

\section{Adsorption Thermodynamic Studies}

To evaluate the thermodynamic feasibility and spontaneous nature of TA adsorbed on MIEX resin, thermodynamic parameters such as standard enthalpy change $\left(\Delta \mathrm{H}^{0}, \mathrm{~kJ} / \mathrm{mol}\right)$, entropy change $\left(\Delta \mathrm{S}^{0}, \mathrm{~J} / \mathrm{mol} \mathrm{K}\right)$, and Gibbs free energy change $\left(\Delta \mathrm{G}^{0}, \mathrm{~kJ} / \mathrm{mol}\right)$ were calculated using equations (12-14) [26]:

$$
\begin{gathered}
K_{\mathrm{D}}=\frac{\left(C_{0}-C_{\mathrm{ad}, e}\right) V}{C_{a d, e} W} \\
\ln K_{D}=\frac{\Delta S^{0}}{R}-\frac{\Delta H^{0}}{R T} \\
\Delta G^{0}=\Delta H^{0}-T \Delta S^{0}
\end{gathered}
$$

...where $\mathrm{K}_{\mathrm{D}}$ is the distribution coefficient $(\mathrm{L} / \mathrm{mL}), \mathrm{C}_{\mathrm{ad}, \mathrm{e}}$ is the amount of TA adsorbed at equilibrium at different adsorption temperatures $(\mathrm{mg} / \mathrm{mL}), \mathrm{R}$ is the universal gas constant $(\mathrm{J} / \mathrm{mol} \mathrm{K}, \mathrm{R}=8.314)$, and $\mathrm{T}$ is the absolute temperature $(\mathrm{K})$.

Furthermore, the average free energy of adsorption (E, $\mathrm{kJ} / \mathrm{mol}$ ) was useful for estimating the adsorption type. It could be calculated from the Dubinin-Radushkevich model [34-35] and described by the following equations (15-17). So the Dubinin-Radushkevich model was applied to fit the adsorption equilibrium data at different adsorption temperatures and calculated the average free energy for the adsorption of TA onto MIEX resin. 
D-R isotherm model:

$$
\begin{gathered}
q_{e}=q_{\max } \exp \left(-B_{D R} \zeta^{2}\right) \\
\zeta=R T \ln \left(1+\frac{1}{C_{e}}\right) \\
E=\frac{1}{\sqrt{2 B D R}}
\end{gathered}
$$

... where $\mathrm{B}_{\mathrm{DR}}$ is the $\mathrm{D}-\mathrm{R}$ model constant $\left(\mathrm{mol}^{2} / \mathrm{J}^{2}\right), \zeta$ is the Polanyi potential $(\mathrm{kJ})$, and $\mathrm{E}$ is the average free energy (J/mol).

Also, the magnitude of apparent activation energy of adsorption can give an idea about what controls the reaction rate of adsorption. The experimental data of kinetics at different solution temperatures (20, 30, and $40^{\circ} \mathrm{C}$ ) were used to calculate the apparent activation energy of TA adsorbed on MIEX resin. The apparent activation energy was calculated by an empirical equation (Arrhenius equation [36]):

$$
\ln \left(k_{2}\right)=\ln A-\frac{E a}{R T}
$$

... where $\mathrm{k}_{2}$ is the rate constant obtained from the pseudo second-order kinetic model $(\mathrm{mL} / \mathrm{mg} \mathrm{min}), \mathrm{Ea}$ is the apparent activation energy of adsorption $(\mathrm{kJ} / \mathrm{mol})$, and A is the Arrhenius factor.

\section{Effects of pH and Coexistent Anions}

The experimental procedure was similar to that of equilibrium experiments. The effect of $\mathrm{pH}$ on the removal of TA was conducted by varying initial $\mathrm{pH}$ of solution (3, $5,7,9,11)$. The initial $\mathrm{pH}$ values of TA solutions were adjusted by adding $0.1 \mathrm{M} \mathrm{HCl}$ or $0.1 \mathrm{M} \mathrm{NaOH}$ solutions when necessary. The effect of anions on the removal of TA was conducted by adding chloride $\left(\mathrm{Cl}^{-}\right)$, sulfate $\left(\mathrm{SO}_{4}^{2}\right)$, and bicarbonate $\left(\mathrm{HCO}_{3}^{-}\right)$into a series of TA solutions with a concentration of $10 \mathrm{mg} / \mathrm{L}$, respectively. Considering the general concentration of anions in surface water sources, each anion in this study was kept at a constant concentration of $1 \mathrm{meq} / \mathrm{L}$.

\section{Desorption}

Based on chloride as the mobile counter ion of MIEX resin, the resin saturated with TA was regenerated by sodium chloride solutions [37]. Batch experiments were conducted in order to select sodium chloride solutions with appropriate concentrations. All experiments were conducted at ambient laboratory temperature and opened to the atmosphere, unless noted otherwise. A fixed dosage (5.0 $\mathrm{mL}$ ) of MIEX resin saturated with TA was added into a set of $800 \mathrm{~mL}$ beakers containing $500 \mathrm{~mL}$ sodium chloride solutions with various concentrations $(0.1 \%$, $0.3 \%, 0.5 \%, 0.7 \%, 0.9 \%)$. Then these solutions were agitated on magnetic stirrers at $150 \mathrm{rpm}$ for $90 \mathrm{~min}$ for desorption. After desorption, the resins were separated and washed with ultra-pure water several times. Then adsorption experiments using the regenerated MIEX resin to remove TA in solutions with a concentration of $10 \mathrm{mg} / \mathrm{L}$ were performed to examine desorption efficacy. High removal of TA implied good desorption. After identifying the appropriate sodium chloride solution for desorption, this kind of chloride solution was used for desorption experiments.

\section{Results and Discussion}

\section{Kinetics of TA Adsorbed on MIEX Resin
Effect of TA Concentration and Adsorption Time on the Removal of TA

The relationship curves of adsorption time, TA concentration, and the amount of removed TA (Eq. 1) are shown in Fig. 1a). The amount of TA adsorbed on MIEX resin increases rapidly within the initial $20 \mathrm{~min}$. This is because in the beginning stage, the virgin MIEX resin has massive vacant adsorption sites, leading to the sharp removal of TA adsorbed on MIEX resin surface. In this stage, the greater TA concentration gradient between bulk solution and the surface of the MIEX resin accelerates the diffusion process of TA from the liquid-phase to solidphase, which may also be a reason for the quick increase in the removal of TA [26]. As adsorption continues (20-80 $\mathrm{min})$, the adsorption rate decreases obviously, compared to the initial stage. This may be attributed to the fact that the removal of TA adsorbed on MIEX resin becomes more difficult due to the reduced available adsorption sites, the narrower TA concentration difference between bulk solution and the surface of resin, and the repulsive forces of TA molecules or ions between on the surface of MIEX resin and in solution. After $80 \mathrm{~min}$, the adsorption finally achieves the equilibrium with no significant change in adsorption uptake. This adsorption phenomenon of three stages is similar to the results of using MIEX resin to remove bromide [26], phosphate [27], and perchlorate [38] from aqueous solutions. Compared with conventional resins, MIEX has a much quicker adsorption rate for the removal of TA due to the much smaller particle diameter [3, 39].

Furthermore, Fig. 1a) also shows that the amount of TA adsorbed on MIEX resin increases with increasing TA concentrations - from 10 to $30 \mathrm{mg} / \mathrm{L}$. At low initial TA concentration, TA molecules or ions are mainly adsorbed on the external adsorption sites of MIEX resin. At high initial TA concentration, however, the greater TA concentration difference between in-solution and on the surface of MIEX makes the TA molecules or ions enter deeply into the internal pores, which ensures that the internal active sites of resin are fully utilized [15]. This may be a reason for causing an increase in uptake with increasing TA concentrations. Other researchers have seen similar results using various adsorbents to remove TA from aqueous solutions $[15,39]$. 

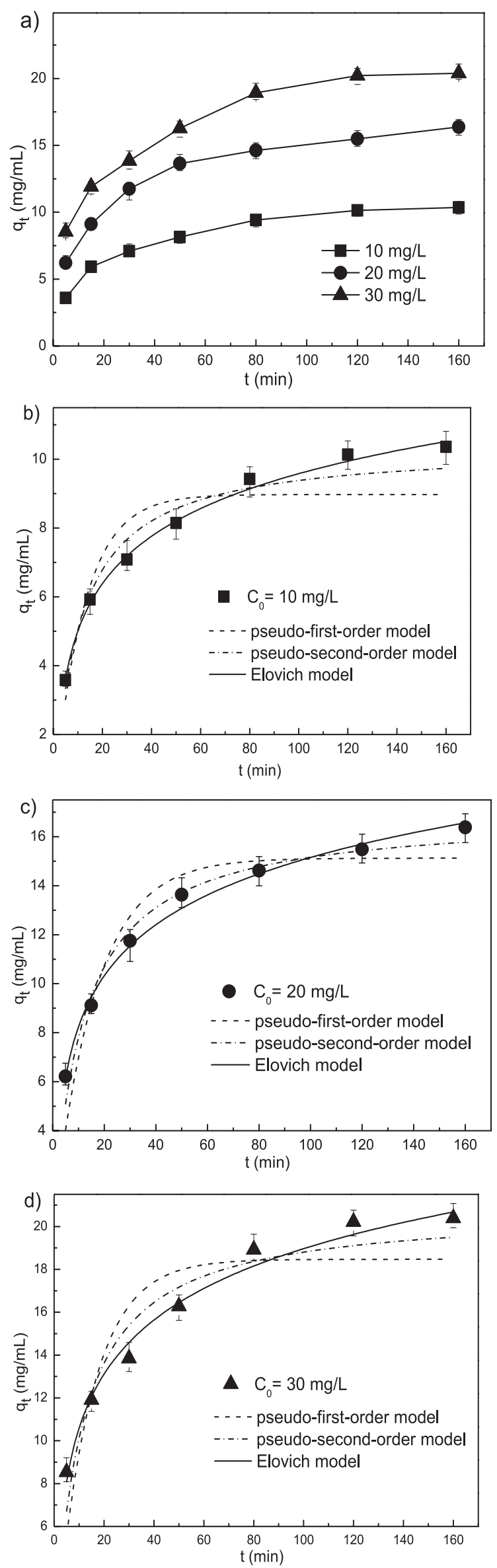

Fig. 1. Effect of adsorption time and initial TA concentration a) and fitted kinetic curves b) $10 \mathrm{mg} / \mathrm{L}$, c) $20 \mathrm{mg} / \mathrm{L}$, d) $30 \mathrm{mg} / \mathrm{L}$.

\section{Kinetics Model of TA Adsorbed on MIEX Resin}

The kinetic data are fitted by three kinetic models: pseudo first-order (Eq. 2), pseudo second-order (Eq. 3), and the Elovich model (Eq. 4). The fitted results are provided in Table 1, and the fitted curves with experimental data are shown in Fig. 1b).

It can be seen from Table 1 that, compared to the pseudo first-order and pseudo second-order models, the correlation coefficients $\left(\mathrm{R}^{2}=0.9864 \sim 0.9976\right)$ of the Elovich model are the highest, and the standard errors $(\mathrm{SE}=0.2916 \sim 0.7131)$ are the lowest. Also, Fig. 1b) demonstrates that the curves fitted by the Elovich model at various TA concentrations approach the experimental data. Accordingly, the Elovich model is the most suitable for depicting the kinetic process of TA adsorbed on MIEX resin. The Elovich model was originally suggested for describing chemical adsorption on heterogeneous surfaces [40]. This indicates that the adsorption process of TA adsorbed on MIEX resin may involve chemisorption.

\section{Diffusion Mechanism}

The intra-particle model (Eq. 5) is used to fit the kinetic data of TA adsorbed on MIEX resin. The intra-particle diffusion plots of $q_{t}$ against $t^{1 / 2}$ are presented in Fig. 2a). Based on the intra-particle diffusion theory, intra-particle diffusion is the only rate-limiting step of adsorption process if the plot of $q_{t}$ against $t^{1 / 2}$ is a straight line and passes through the origin. Otherwise, other steps along with intra-particle diffusion might also be involved [41]. From Fig. 2a) we observed that the plots of $q_{t}$ versus $t^{1 / 2}$ are not linear within the whole adsorption time, but each plot is divided into two segments and each segment gives a good linear form, but they do not all pass through the origin. These results indicate that intra-particle diffusion is not the only rate-limiting step, and that other diffusion processes, such as liquid film diffusion, may affect the adsorption rate of TA adsorbed on MIEX resin. The first linear portion means the intra-particle dominates the adsorption rate, but the film diffusion also exists because the intercepts are not equal to zero [42]. And the second linear portion represents the final equilibrium stage where intra-particle diffusion is very slow due to the extremely low TA concentration in solution [16]. A similar type of pattern has been reported for organic pollution adsorbed on porous adsorbents $[12,41,43]$.

To ascertain the factual rate-limiting step of the adsorption process, the Boyd model (Eqs. 6-8) was used to further fit the kinetic data of TA adsorbed on MIEX resin, and the results fitted by the Boyd model are given in Fig. 2b). Based on the Boyd model theory, the process of TA adsorbed on MIEX resin are controlled by the intra-particle step if the plots of Bt versus $t$ are linear and pass through the origin; otherwise, the adsorption rate is controlled by liquid film diffusion [44]. As clearly shown in Fig. 2b), although Boyd plots give linear forms at different initial TA concentrations, they both do not pass the origin, implying that the adsorption rate of TA 

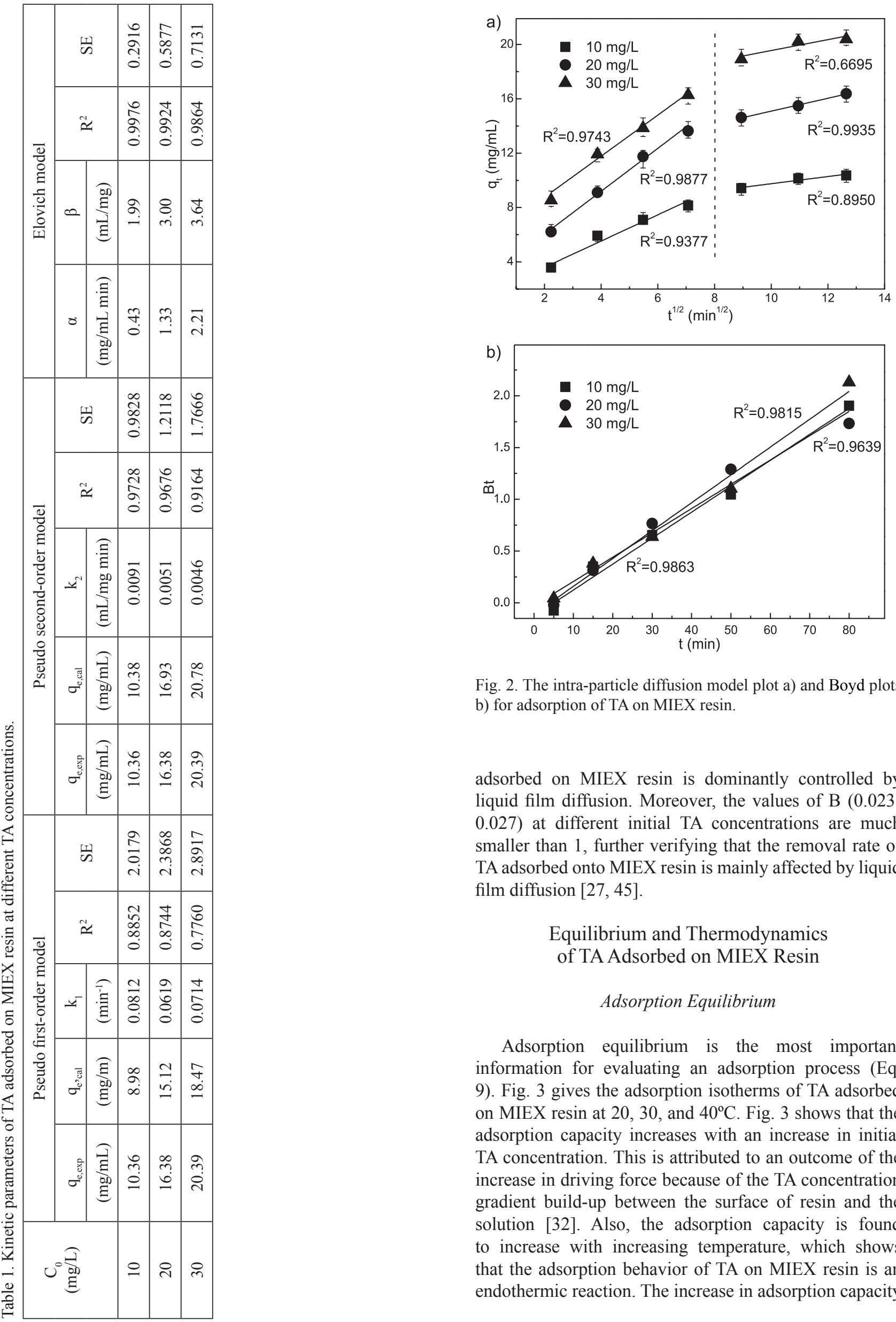

Fig. 2. The intra-particle diffusion model plot a) and Boyd plots b) for adsorption of TA on MIEX resin.

adsorbed on MIEX resin is dominantly controlled by liquid film diffusion. Moreover, the values of B (0.0230.027 ) at different initial TA concentrations are much smaller than 1, further verifying that the removal rate of TA adsorbed onto MIEX resin is mainly affected by liquid film diffusion $[27,45]$.

Equilibrium and Thermodynamics of TA Adsorbed on MIEX Resin

\section{Adsorption Equilibrium}

Adsorption equilibrium is the most important information for evaluating an adsorption process (Eq. 9). Fig. 3 gives the adsorption isotherms of TA adsorbed on MIEX resin at 20,30 , and $40^{\circ} \mathrm{C}$. Fig. 3 shows that the adsorption capacity increases with an increase in initial TA concentration. This is attributed to an outcome of the increase in driving force because of the TA concentration gradient build-up between the surface of resin and the solution [32]. Also, the adsorption capacity is found to increase with increasing temperature, which shows that the adsorption behavior of TA on MIEX resin is an endothermic reaction. The increase in adsorption capacity 

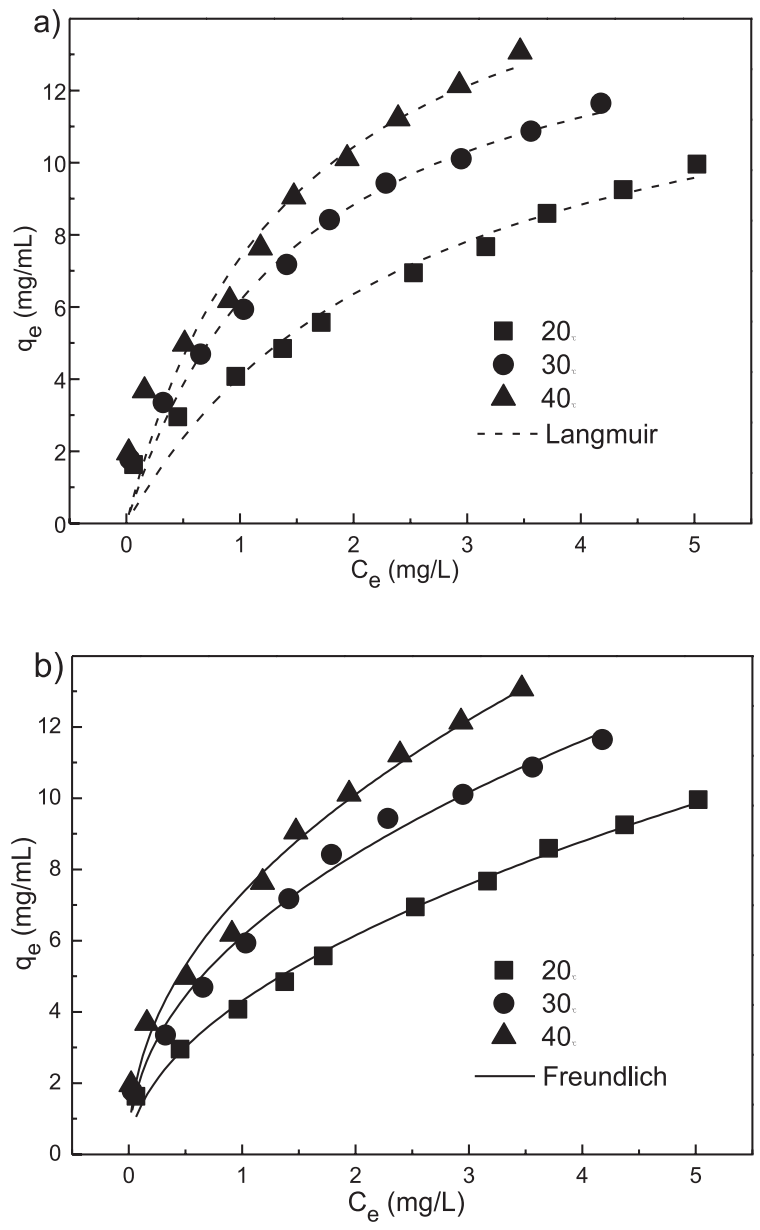

Fig. 3. Adsorption equilibrium of TA on MIEX resin at different temperatures: a) Langmuir isotherm, b) Freundlich isotherm.

with temperature can be due to the increase in the rate of intra-particle adsorbate molecules or ions into the pores of adsorbent at higher temperature [32]. In addition, the increased adsorption capacity may also be attributed to the fact that the higher temperature activates the resin surface and/or creates new active sites on adsorbent surface [16]. Many adsorbents, such as commercial-activated carbon [16], magnetic carbohydrate natural polymer [44], amino-functionalized magnetic nanoadsorbent [13], and commercial ester resin XAD-7 [1], demonstrated a similar isotherm for the removal of TA from aqueous solutions.

The Langmuir (Eq. 10) and Freundlich (Eq. 11) isotherm models were used to validate the equilibrium adsorption data, and the results are presented in Table 2, which shows that - compared to the Langmuir model - the fit to equilibrium data with the Freundlich model is better with higher values of correlation coefficient $\left(R^{2}>0.98\right)$ and lower values of standard error $(\mathrm{SE}=0.2431-0.5022)$. Therefore, the Freundlich isotherm model is reliable for describing the adsorption equilibrium performances of TA on MIEX resin. The Langmuir model assumes that the adsorption occurs at the homogeneous surface, adsorbate is adsorbed on the surface of adsorbent in a monolayer behavior, and no interaction exists among the adsorbed species [46]. For a complex adsorption system, however, it is far more difficult to satisfy these harsh demands. This may be why the Langmuir model cannot simulate well the equilibrium of TA adsorbed on MIEX resin. The Freudlich model, however, was suggested for describing heterogeneous or multilayer adsorption behavior [13]. For MIEX resin, it has many pores on the external and internal surface, indicating that the surface of the adsorbent is heterogeneous. In addition, Zhao et al. suggested that the Freudlich model could give good simulation to the equilibrium data at low and intermediate adsorbate concentrations [47]. In the present study, the TA concentration ranges from 1 to $10 \mathrm{mg} / \mathrm{L}$, which is consistent with the assumption of the Freudlich model. These may be the reasons that the Freudlich isotherm model gives good simulation. The value of $\mathrm{k}_{\mathrm{f}}$ is the Freundlich constant related to the bonding energy and adsorption capacity, and the larger the value of $\mathrm{k}_{\mathrm{f}}$, the greater the affinity of adsorbate to adsorbent $[33,48]$. Table 2 demonstrates that the value of $\mathrm{k}_{\mathrm{f}}$ increases from 4.3051 to 7.3239 with an increase in temperature from 293 to $313 \mathrm{~K}$, showing that higher temperature favors the TA adsorbed on MIEX resin. Another Freundlich constant, $1 / \mathrm{n}$, gives an indication of a favorable adsorption process; the adsorption is called preferential adsorption if $1 / \mathrm{n}$ is between 0 and 1 [26]. As can be seen from Table 2, the values of $1 / \mathrm{n}$ at different temperatures range from 0 to 1 , indicating that the adsorption of TA on MIEX resin is preferred.

\section{Adsorption Thermodynamics}

Based on the equilibrium adsorption data, the distribution coefficients $\left(\mathrm{K}_{\mathrm{D}}\right)$ of the adsorption of TA using MIEX resin are evaluated by Eq. 12. The values of $\Delta \mathrm{H}^{0}$ and $\Delta \mathrm{S}^{0}$ (Eq. 13) can be obtained from the slope and intercept of the plot of $\ln \mathrm{K}_{\mathrm{D}}$ against $1000 / \mathrm{T}$ (Fig. 4). The Gibbs free energy change, $\Delta \mathrm{G}^{0}$, is calculated by Eq. 14. And all the calculated thermodynamic results are

Table 2. Constant, correlation coefficients, and SE of Langmuir and Freundlich isotherm models

\begin{tabular}{|c|c|c|c|}
\hline $\mathrm{T}\left({ }^{\circ} \mathrm{C}\right)$ & 20 & 30 & 40 \\
\hline \multicolumn{4}{|c|}{ Langmuir isotherm model constants } \\
\hline $\mathrm{b}(\mathrm{L} / \mathrm{mg})$ & 0.3927 & 0.6594 & 0.6923 \\
\hline $\mathrm{q}_{\max }(\mathrm{mg} / \mathrm{mL})$ & 14.46 & 15.52 & 17.97 \\
\hline $\mathrm{R}^{2}$ & 0.9573 & 0.9683 & 0.9322 \\
\hline SE & 0.5766 & 0.5940 & 0.9756 \\
\hline \multicolumn{4}{|c|}{ Freundlich isotherm model constants } \\
\hline $\mathrm{k}_{\mathrm{f}}$ & 4.3051 & 6.1205 & 7.3239 \\
\hline $1 / \mathrm{n}$ & 0.5145 & 0.4618 & 0.4647 \\
\hline $\mathrm{R}^{2}$ & 0.9924 & 0.9887 & 0.9821 \\
\hline SE & 0.2431 & 0.3542 & 0.5022 \\
\hline
\end{tabular}


summarized in Table 3.

The positive values of $\Delta \mathrm{H}^{0}$ show the endothermic nature of TA adsorbed on MIEX resin, further confirming the result found in the equilibrium experiments. Growth of temperature is favorable for increasing the probability of TA adsorbed on MIEX resin. Generally, chemical adsorption is considered to predominate the adsorption process if the enthalpy change is more than $40 \mathrm{~kJ} / \mathrm{mol}$; otherwise the physical properties predominate the adsorption process [49-50]. Table 4 demonstrates that enthalpy changes at low TA concentrations of 1.0 and 2.0 $\mathrm{mg} / \mathrm{L}(53.24$ and $48.08 \mathrm{~kJ} / \mathrm{mol}$, respectively), showing they are more than $40 \mathrm{~kJ} / \mathrm{mol}$. This implies that chemical behavior predominates the adsorption process of TA on MIEX resin at low TA concentrations. Under these conditions, the ion-exchange sites on the surface of MIEX resin are sufficient to exchange with the TA in solution, and the chemical reaction (ion exchange) occurs. However, the enthalpy changes are less than $40 \mathrm{~kJ} / \mathrm{mol}$ as the TA concentration increases from 3 to $10 \mathrm{mg} / \mathrm{L}$, indicating the physical adsorption accounts for the domination. The positive values of $\Delta \mathrm{S}^{0}$ show that the degree of disorder on the solid-liquid interface increases after adsorption, demonstrating good affinity of MIEX resin for TA [26]. The values for standard Gibbs free energy $\Delta G^{0}$ are negative at all temperatures shown in this study, indicating that the adsorption of TA by MIEX resin is thermodynamically feasible and spontaneous without any induction period [16]. Meanwhile, $\Delta \mathrm{G}^{0}$ values become more negative when increasing the temperature of solution from $20^{\circ} \mathrm{C}$ to $40^{\circ} \mathrm{C}$, implying that increasing temperature has a positive effect on the adsorption reaction of TA on MIEX resin. However, at the identical temperature the $\Delta \mathrm{G}^{0}$ values become less negative with an increase in TA concentration from 1 to $10 \mathrm{mg} / \mathrm{L}$, indicating that the adsorption becomes more difficult spontaneously. In general, the value of $\Delta G^{0}$ for physical adsorption is between -20 and $0 \mathrm{~kJ} / \mathrm{mol}$, and -400 and $-80 \mathrm{~kJ} / \mathrm{mol}$ for chemical adsorption [45]. The values of $\Delta \mathrm{G}^{0}$ range from -12.08 to $-1.67 \mathrm{~kJ} / \mathrm{mol}$, showing that the

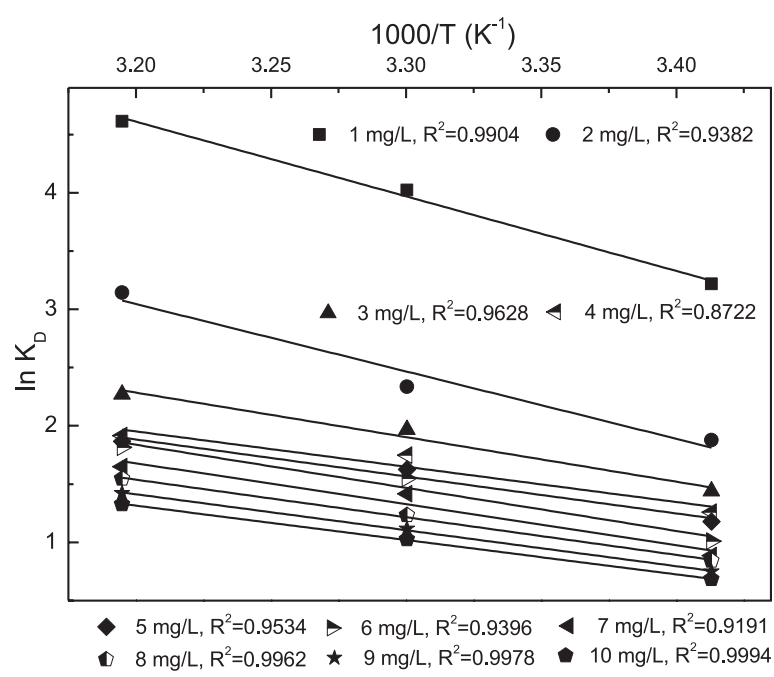

Fig. 4. Plots of $\ln K_{D}$ versus $1 / T$ for the adsorption of TA on MIEX resin.

adsorption of TA onto MIEX resin is physical adsorption. Basically, this result is consistent with that obtained from the enthalpy changes.

Also, average free energy ( $\mathrm{E}, \mathrm{kJ} / \mathrm{mol})$ of adsorption process can be used to estimate the adsorption type. According to equations 15-17, the values of $\mathrm{E}$ of TA adsorbed on MIEX resin can be evaluated from the Dubinin-Radushkevich isotherm model, and the results are presented in Table 4, which shows that the values of average free energy of TA adsorbed onto MIEX resin at three various temperatures are all less than $8 \mathrm{~kJ} / \mathrm{mol}$, indicating that the adsorption involves physical sorption [51-52]. Furthermore, the values of $\mathrm{B}_{\mathrm{DR}}$, which are far less than 1, indicate that the porous structure of MIEX resin plays an important role in the adsorption process [53].

The apparent activation energy of the adsorption process, $\mathrm{Ea}(\mathrm{kJ} / \mathrm{mol})$, is useful for differentiating adsorption types. The value of $\mathrm{k}_{2}$ can be obtained by using the pseudo

Table 3. Thermodynamic parameters of TA adsorption on MIEX resin.

\begin{tabular}{|c|c|c|c|c|c|c|c|c|}
\hline $\mathrm{C}_{0}$ & \multicolumn{3}{|c|}{$\mathrm{K}_{\mathrm{D}}$} & $\Delta \mathrm{H}^{0}$ & \multicolumn{1}{c|}{$\Delta \mathrm{S}^{0}$} & \multicolumn{3}{c|}{$\Delta \mathrm{G}^{0}(\mathrm{~kJ} / \mathrm{mol})$} \\
\hline$(\mathrm{mg} / \mathrm{L})$ & $20^{\circ} \mathrm{C}$ & $30^{\circ} \mathrm{C}$ & $40^{\circ} \mathrm{C}$ & $\mathrm{kJ} / \mathrm{mol}$ & $\mathrm{J} / \mathrm{mol} \mathrm{K}$ & $20^{\circ} \mathrm{C}$ & $30^{\circ} \mathrm{C}$ & $40^{\circ} \mathrm{C}$ \\
\hline 1 & 24.9939 & 55.8616 & 100.8278 & 53.24 & 208.71 & -7.91 & -9.99 & -12.08 \\
\hline 2 & 6.5287 & 10.3267 & 23.1414 & 48.08 & 179.17 & -4.42 & -6.21 & -8.00 \\
\hline 3 & 4.2170 & 7.1547 & 9.6822 & 31.77 & 120.66 & -3.58 & -4.79 & -6.00 \\
\hline 4 & 3.5196 & 5.7400 & 6.7922 & 25.19 & 96.83 & -3.18 & -4.15 & -5.12 \\
\hline 5 & 3.2448 & 5.0837 & 6.4688 & 26.38 & 100.07 & -2.94 & -3.94 & -4.94 \\
\hline 6 & 2.7457 & 4.7043 & 6.1334 & 30.74 & 113.65 & -2.56 & -3.69 & -4.83 \\
\hline 7 & 2.4234 & 4.1237 & 5.2068 & 29.27 & 107.63 & -2.26 & -3.34 & -4.42 \\
\hline 8 & 2.3207 & 3.4274 & 4.6898 & 26.84 & 98.68 & -2.07 & -3.06 & -4.05 \\
\hline 9 & 2.1152 & 3.0526 & 4.1438 & 25.65 & 93.83 & -1.84 & -2.78 & -3.72 \\
\hline 10 & 1.9817 & 2.7881 & 3.7678 & 24.50 & 89.34 & -1.67 & -2.57 & -3.46 \\
\hline
\end{tabular}


Table 4. Average free energy and the apparent activation energy of TA adsorption on MIEX resin at 20, 30, and $40^{\circ} \mathrm{C}$.

\begin{tabular}{|c|c|c|c|c|c|c|c|c|}
\hline $\mathrm{T}$ & \multicolumn{2}{|c|}{ Dubinin-Radushkevich isotherm model } & $\mathrm{E}$ & \multicolumn{2}{c|}{ Pseudo second-order model } & Ea \\
\hline${ }^{\circ} \mathrm{C}$ & $\mathrm{B}_{\mathrm{DR}}\left(\mathrm{mol}^{2} / \mathrm{kJ}^{2}\right)$ & $\begin{array}{c}\mathrm{q}_{\max } \\
(\mathrm{mg} / \mathrm{mL})\end{array}$ & $\mathrm{R}^{2}$ & $(\mathrm{KJ} / \mathrm{mol})$ & $\begin{array}{c}\mathrm{q}_{\max } \\
(\mathrm{mg} / \mathrm{mL})\end{array}$ & $\begin{array}{c}\mathrm{k}_{2} \\
(\mathrm{mg} / \mathrm{mL} \min )\end{array}$ & $\mathrm{R}^{2}$ & $(\mathrm{~kJ} / \mathrm{mol})$ \\
\hline 20 & 0.6307 & 12.28 & 0.9312 & 0.89 & 17.56 & 0.0010 & 0.9942 & \\
\hline 30 & 0.4711 & 14.42 & 0.9602 & 1.03 & 17.79 & 0.0012 & 0.9896 & 11.53 \\
\hline 40 & 0.4079 & 16.06 & 0.9228 & 1.11 & 18.21 & 0.0014 & 0.9869 & \\
\hline
\end{tabular}

second-order model (Eq. 3) to fit the kinetics data of TA adsorbed on MIEX resin at different temperatures (293, 303 , and $313 \mathrm{~K}$ ), and the results are shown in Table 4. Then, according to Eq. 18, Ea (given in Table 4) of the adsorption process of TA on MIEX resin can be obtained by the slope of the plot (shown in Fig. 5) of $\ln \left(\mathrm{k}_{2}\right)$ against $1 / \mathrm{T}$. It is observed that the plot of $\ln \left(\mathrm{k}_{2}\right)$ against $1 / \mathrm{T}$ gives a good straight line. Based on the slope of straight line, the value of Ea is $11.53 \mathrm{~kJ} / \mathrm{mol}$. Many researchers have reported that the adsorption process followed physical adsorption when activation energy ranged from 5 to $40 \mathrm{~kJ} / \mathrm{mol}$ [54-55]. Based on the above viewpoint, the adsorption of TA on MIEX involves physisorption. Also, $M$. Hamayun reported that when the activation energy was less than $42 \mathrm{~kJ} / \mathrm{mol}$, the diffusion process was involved in the adsorption [32]. This is consistent with the result (film diffusion controls the whole adsorption rate) from the kinetic analysis.

Considered comprehensively, the results obtained from the energy changes analysis during the adsorption of TA adsorbed on MIEX resin, we propose that the adsorption of TA onto MIEX resin is considered to be the physical adsorption. However, previous researchers have demonstrated that the removal of NOM adsorbed on MIEX was considered to be chemical adsorption (ion exchange) mainly dominating adsorption [24]. In the present study we only give the finding that the adsorption of TA on MIEX resin involves physical adsorption. As for the interactive forces involved in the process of

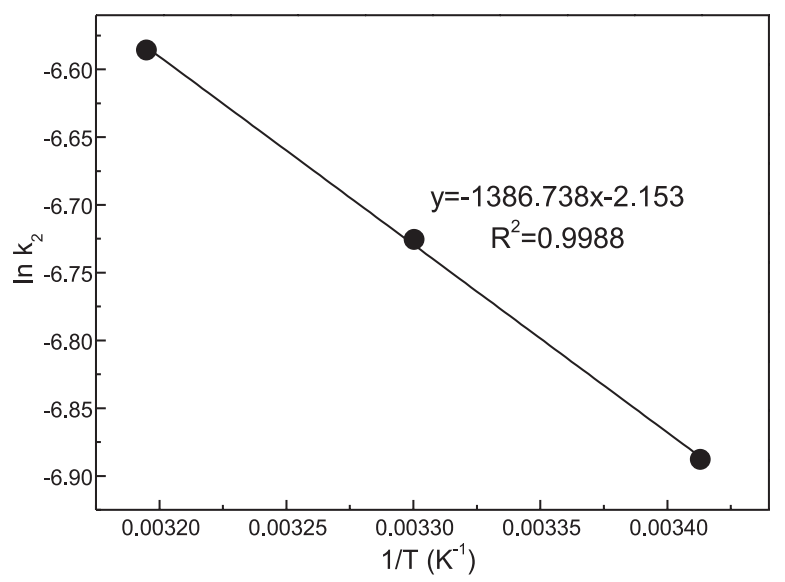

Fig. 5. The plot for calculating the apparent activation energy for TA adsorption on MIEX resin. physical adsorption, the removal mechanism of TA will be elaborated upon in another paper by characterizing MIEX resin before and after adsorption.

\section{The Impact of Factors and Desorption of MIEX Resin on TA Adsorption}

\section{Effect of Initial pH of Solution}

The $\mathrm{pH}$ of a solution is an important variable that governs the adsorption system by controlling the surface properties of adsorbents and adsorbate form [2]. Fig. 6a) reflects the effect of initial $\mathrm{pH}$ of solution on the removal
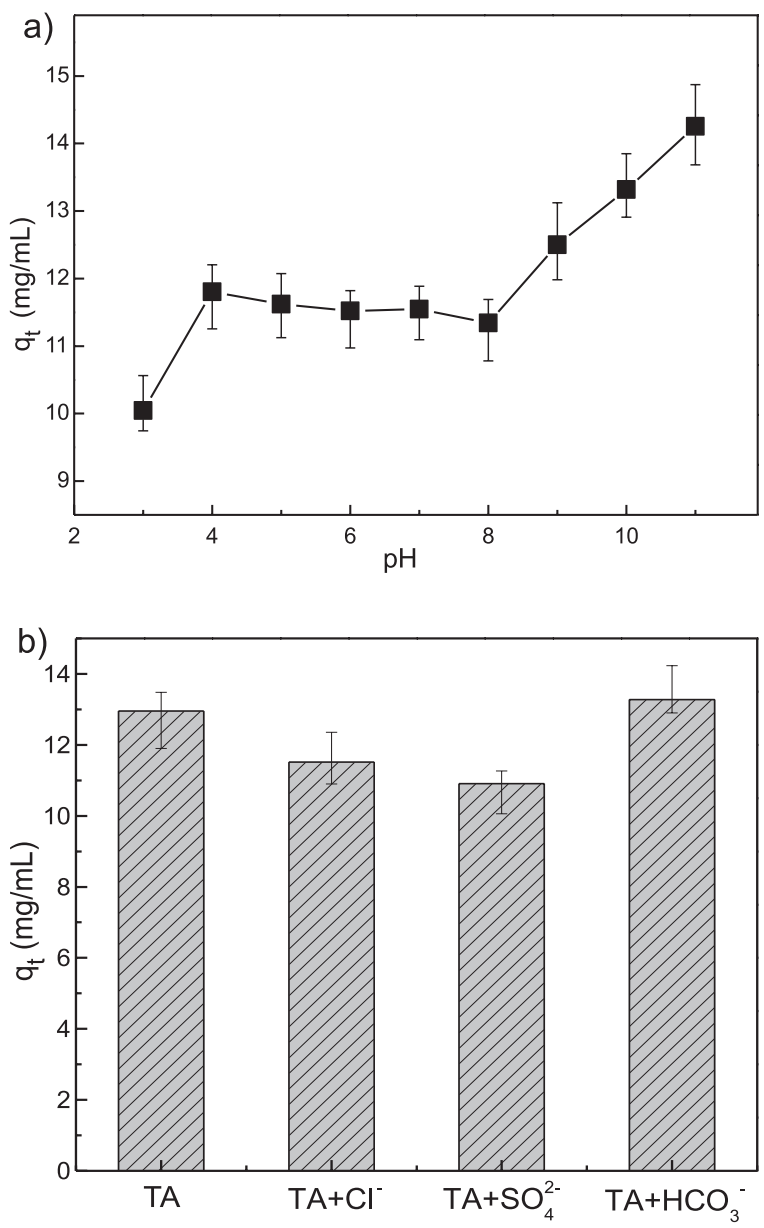

Fig. 6. Effect of $\mathrm{pH}$ of solution a) and coexistent anions b) on TA removal. 
Table 5. Comparison of the maximum adsorption capacity of tannic acid onto various adsorbents.

\begin{tabular}{|c|c|c|c|c|c|}
\hline \multirow[b]{2}{*}{ Adsorbent } & \multirow{2}{*}{$\begin{array}{c}\mathrm{q}_{\max } \\
(\mathrm{mg} / \mathrm{g})\end{array}$} & \multicolumn{3}{|c|}{ Conditions } & \multirow[b]{2}{*}{ Reference } \\
\hline & & $\mathrm{C}_{0}(\mathrm{TA})(\mathrm{mg} / \mathrm{L})$ & Adsorption time & $\begin{array}{l}\text { Adsorbent dosage } \\
\qquad(\mathrm{g} / \mathrm{L})\end{array}$ & \\
\hline Commercial resins D-201 & 238 & & 5 days & 2 & {$[1]$} \\
\hline $\begin{array}{l}\text { Surfactant-modified zeolites with } \\
\text { loadings of cetylpyridinium bromide }\end{array}$ & 111 & $15-100$ & $24 \mathrm{~h}$ & 0.5 & {$[2]$} \\
\hline Activated carbon & 340.8 & $200-1,000$ & & 2 & {$[12]$} \\
\hline $\begin{array}{l}\text { Amino-functionalized magnetic } \\
\text { nanoadsorbent }\end{array}$ & 136.2 & $10-100$ & $24 \mathrm{~h}$ & 0.4 & {$[13]$} \\
\hline $\begin{array}{l}\text { Amino-functionalized magnetic } \\
\text { mesoporous silica }\end{array}$ & 510.2 & $20-200$ & $24 \mathrm{~h}$ & 0.2 & {$[15]$} \\
\hline $\begin{array}{l}\text { Magnetic strongly basic anion } \\
\text { exchange resin (MAEX) }\end{array}$ & 192.1 & $0-150$ & $24 \mathrm{~h}$ & 1 & {$[22]$} \\
\hline Polyaniline & 84.8 & $10-100$ & $24 \mathrm{~h}$ & 0.5 & {$[37]$} \\
\hline Chitosan-coated attapulgite & 95.2 & $5-200$ & & 0.25 & {$[48]$} \\
\hline Zr-pillared montmorillonite & 66 & $51-510$ & $6 \mathrm{~h}$ & 2 & [49] \\
\hline Zirconium pillared clay & 86.5 & & $4 \mathrm{~h}$ & 2 & {$[50]$} \\
\hline MIEX resin & 112.3 & $0-10$ & $150 \mathrm{~min}$ & 0.08 & This work \\
\hline
\end{tabular}

of TA adsorbed on MIEX resin. The adsorption capacity of TA on MIEX resin keeps approximately steady (about $11.60 \mathrm{mg} / \mathrm{mL}$ ) by increasing the value of $\mathrm{pH}$ from 4 to 8 . It is of extreme significance for drinking water treatment plants not to be unnecessary to adjust $\mathrm{pH}$ of raw water due to the fact that the $\mathrm{pH}$ of raw water ranges usually from 6 to 9. The adsorption capacity of TA on MIEX resin decreases from 11.80 to $10.04 \mathrm{mg} / \mathrm{mL}$ when decreasing the initial $\mathrm{pH}$ from 4 to 3 . At lower $\mathrm{pH}(\mathrm{pH}=3)$, the protonation of tannic acid is close to $100 \%$, indicating that TA exists in its molecular form $[12,48]$. Therefore, the disappearance of electrostatic attraction between MIEX resin and TA may be a reason for the decrease in the removal of TA. But at $\mathrm{pH}=3$, the capacity of adsorption still keeps to a certain level $(10.04 \mathrm{mg} / \mathrm{mL})$. The hydrogen bonding and organic partitioning may be responsible for the removal of TA adsorbed on MIEX at $\mathrm{pH}=3$ [2]. When the initial $\mathrm{pH}$ of solution increased from 8 to 11 , the adsorption capacity of TA on MIEX resin increased rapidly from 11.34 to $14.25 \mathrm{mg} / \mathrm{mL}$, showing that alkalinity furthers the removal of TA adsorbed on MIEX resin. However, many researchers have reported that the removal of TA adsorbed on various adsorbents decreased with increasing $\mathrm{pH}$ when $\mathrm{pH}$ is above $8[2,12-13,15]$. Also, the removal of anions (such as bromide, phosphate) using MIEX resin decreased when $\mathrm{pH}$ was above 8 [26-27]. The reasons causing the obvious difference have not been determined.

\section{Effect of Coexistent Anions}

Various inorganic anions such as chloride, sulfate, and bicarbonate are typically found in natural water bodies. They can complete for the active adsorption sites due to the different affinities on the MIEX resin surface
[26]. Fig. 6b) gives the effects of different anions such as $\mathrm{Cl}^{-}, \mathrm{SO}_{4}^{2-}$, and $\mathrm{HCO}_{3}^{-}$on the TA adsorbed on MIEX resin. The amount of TA adsorbed on MIEX resin is
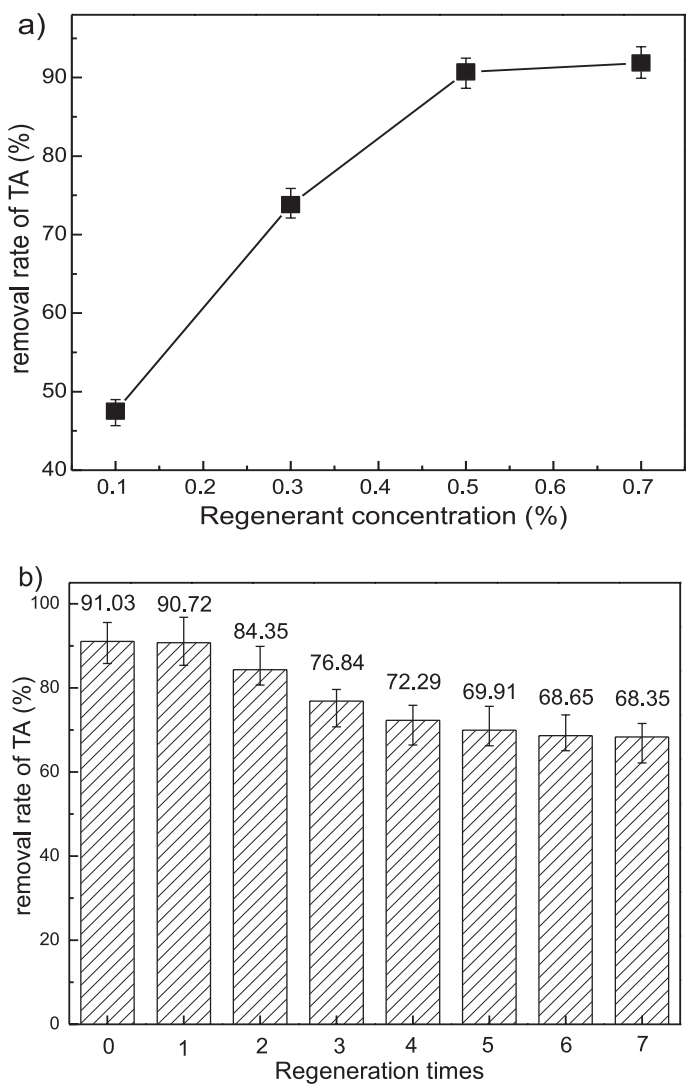

Fig. 7. a) Effect of regenerant concentrations on regeneration; b) effect of multiple regeneration cycles on TA removal. 
$12.95 \mathrm{mg} / \mathrm{mL}$ when no other anions are added into TA solution. However, after chloride and sulfate are added into TA solution, we obtained uptakes of 11.52 and $10.91 \mathrm{mg} / \mathrm{mL}$, respectively. This indicates that chloride and sulfate could cause a decline in the amount of TA adsorbed on MIEX resin to a certain extent. This can be explained by the fact that the competition between chloride or sulfate and TA for the adsorption active sites of MIEX resin surface occurs. Conversely, the uptake increases from 12.95 to $13.28 \mathrm{mg} / \mathrm{mL}$ after adding bicarbonate into TA solution, showing that bicarbonate furthers the removal of TA. The reaction of bicarbonate with phenolic hydroxyl groups leads to the ionization of TA molecular, making it easy to remove TA by ion exchange action. This may be a reason why bicarbonate promotes the removal of TA. A similar promotion was found during the removal of phosphate adsorbed on MIEX resin [27].

\section{Comparison with Other Adsorbents}

Table 5 gives the comparison with different adsorbents for the removal of TA from aqueous solutions. Although the adsorption capacity of TA adsorbed on MIEX resin is not the highest, the time needed to reach equilibrium is far shorter compared with other adsorbents. This is attributed to the smaller size of MIEX resin causing fast adsorption. The advantage of a short time reaching equilibrium is of extreme significance for diminishing the size of adsorption facilities.

\section{Desorption and Recyclability}

Fig. 7a) shows the relationship of the regenerant (sodium chloride) concentration and desorption efficacy. The removal efficiency of TA adsorbed on regenerated MIEX resin does not obviously change after the concentration of sodium chloride is increased to $0.5 \%$. Therefore, the regenerant concentration of $0.5 \%$ is used for subsequent adsorption-desorption recyclability experiments. Fig. $7 b$ ) reflects that after the seventh cycle of adsorption-desorption, the removal efficiency of TA adsorbed on regenerated MIEX resin is still close to $70 \%$. This shows that the regenerated MIEX resin can be used as a promising adsorbent for the removal of TA from raw water. In addition, the desorption efficacy decreases with multiple cycles of adsorption-desorption, showing that some adsorption sites saturated by TA are difficult to regenerate by ion exchange action of sodium solution. This may imply that other removal mechanisms of TA adsorbed on MIEX resin may occur, such as physical interaction, besides ion exchange.

\section{Conclusions}

In this study we investigated the removal performances of tannic acid adsorbed on MIEX resin and came to the following conclusions:
1) The adsorption of TA on MIEX resin is a quick process, and the adsorption equilibrium can be reached after 80 min. The Elovich kinetic model is the most suitable for depicting the kinetic process of TA adsorbed on MIEX resin. And the liquid film diffusion dominates the whole adsorption rate.

2) The Freundlich isotherm model is reliable for describing adsorption equilibrium performances. Adsorption is a thermodynamically feasible, endothermic, entropydriving, and spontaneous process that involves physical adsorption.

3) MIEX resin can effectively remove TA from raw water at $\mathrm{pH}$ 6-9. The presence of chloride and sulfate in solution has an adverse effect on the removal of TA. Conversely, bicarbonate can further the removal of TA. A sodium chloride solution with a concentration of $0.5 \%$ can effectively regenerate the MIEX resin saturated by TA. The regenerated MIEX resin can be used circularly as an adsorbent for the removal of TA from aqueous solution.

\section{Acknowledgements}

This work was supported by the National Natural Science Foundation of China (grant No. 51308001), the China Scholarship Council (No. 201408340033), and the Innovation Research Funds of Anhui University of Technology for Graduates (No. 2012038).

\section{References}

1. WANG J.N., LI A.M., XU L., ZHOU Y. Adsorption studies of tannic acid by commercial ester resin XAD-7. Chinese J Polym Sci 28 (2), 231, 2010.

2. LIN J.W., ZHAN Y.H., ZHU Z.L., XING Y.Q. Adsorption of tannic acid from aqueous solution onto surfactant-modified zeolite. J Hazard Mater 193 (193), 102, 2011.

3. SUN Y., LI A.M., ZHANG Q.X., CHEN J.L., FU D.F., WANG S.H. Adsorptive separation of tannic acid from aqueous solution by polymeric resins. Sep Sci Technol $\mathbf{4 3}$ (2), 389, 2008.

4. ABDULLAH A.M., HUSSONA S.E.D. Predictive model for disinfection by-product in Alexandria drinking water, northern west of Egypt. Environ Sci Pollut R 20 (10), 7152, 2013.

5. DOEDERER K., GEMJAK W., WEINBERG H.S., FARRE M.J. Factors affecting the formation of disinfection byproducts during chlorination and chloramination of secondary effluent for the production of high quality recycled water. Water Research 48 (1), 218, 2014.

6. BENÍTEZ F.J., ACERO J.L., LEAL A.I., REAL F.J. Ozone and membrane filtration based strategies for the treatment of cork processing wastewaters. J Hazard Mater 152 (1), 373, 2008.

7. BUSO A., BALBO L., GIOMO M., FARNIA G., SANDONA G. Electrochemical removal of tannins from aqueous solutions. Ind Eng Chem Res 39 (2), 494, 2000.

8. CHIANG P.C., CHANG E.E., CHANG P.C., HUANG C.P. Effects of pre-ozonation on the removal of THM precursors by coagulation. Sci Total Environ 407 (21), 5735, 2009. 
9. LI W.W., LI X.D., ZENG K.M. Aerobic biodegradation kinetics of tannic acid in activated sludge system. Biochem Eng J 43 (2), 142, 2009.

10. CAÑIZARES P., PÉREZ Á., CAMARILLO R., LLANOS J. Tannic acid removal from aqueous effluents using micellar enhanced ultrafiltration at pilot scale. Desalination 200 (1), $310,2006$.

11. WANG L., CHU H.Q., DONG B.Z. Effects on the purification of tannic acid and natural dissolved organic matter by forward osmosis membrane. J Membrane Sci 455 (4), 31, 2014.

12. SARICI-OZDEMIR C., ONAL Y. Equilibrium, kinetic and thermodynamic adsorptions of the environmental pollutant tannic acid onto activated carbon. Desalination 251 (1), 146, 2010.

13. WANG J.H., ZHENG C.L., DING S.L., MA H.R., JI Y.F. Behaviors and mechanisms of tannic acid adsorption on an amino-functionalized magnetic nanoadsorbent. Desalination 273 (2-3), 285, 2011

14. CHANG M.Y., JUANG R.S. Adsorption of tannic acid, humic acid, and dyes from water using the composite of chitosan and activated clay. J Colloid Interf Sci 278 (1), 18, 2004.

15. WANG J.H., ZHENG S.R., LIU J.L., XU Z.Y. Tannic acid adsorption on amino-functionalized magnetic mesoporous silica. Chemical Engineering Journal 165 (1), 10, 2010.

16. SINGH S., KUSHWAHA J.P. Tannic acid adsorption/ desorption study onto/from commercial activated carbon. Desalin Water Treat 52 (52), 3301, 2014.

17. FU F.L., WANG Q. Removal of heavy metal ions from wastewaters: A review. J Environ Manage 92 (3), 407, 2011.

18. GRAF K.C., CORNWELL D.A., BOYER T.H. Removal of dissolved organic carbon from surface water by anion exchange and adsorption: Bench-scale testing to simulate a two-stage countercurrent process. Sep Purif Technol 122 (3), 523, 2014.

19. HANIGAN D., INNISS E., CLEVENGER T.E. MIEX (R) and PAC for removal of hydrophilic DBP precursors. J Am Water Works Ass 105 (3), 41, 2013.

20. ZHANG R., VIGNESWARAN S., NGO H.H., NGUYEN H. Magnetic ion exchange (MIEX $\left.{ }^{\circledR}\right)$ resin as a pre-treatment to a submerged membrane system in the treatment of biologically treated wastewater. Desalination 192 (1), 296, 2006.

21. NGUYEN T.V., ZHANG R., VIGNESWARAN S., NGO H.H., KANDASAMY J., MATHES P. Removal of organic matter from effluents by Magnetic Ion Exchange (MIEX (R)). Desalination 276 (1), 96, 2011.

22. FU L.C., LIU F.Q., MA Y., TAO X.W., LING C., LI A.M., SHUANG C.D., LI Y. High-efficient technique to simultaneous removal of $\mathrm{Cu}(\mathrm{II}), \mathrm{Ni}(\mathrm{II})$ and tannic acid with magnetic resins: Complex mechanism behind integrative application. Chemical Engineering Journal 263, 83, 2015.

23. ZHANG X.X., LU X., LI S., ZHONG M.Y., SHI X.D., LUO G., DING L. Investigation of 2,4-dichlorophenoxyacetic acid adsorption onto MIEX resin: Optimization using response surface methodology. J Taiwan Inst Chem E 45 (4), 1835,2014

24. APELL J.N., BOYER T.H. Combined ion exchange treatment for removal of dissolved organic matter and hardness. Water Research 44 (8), 2419, 2010.

25. BOYER T.H., SINGER P.C. A pilot-scale evaluation of magnetic ion exchange treatment for removal of natural organic material and inorganic anions. Water Research 40 (15), 2865, 2006.
26. DING L., DENG H.P., WU C., HAN X. Affecting factors, equilibrium, kinetics and thermodynamics of bromide removal from aqueous solutions by MIEX resin. Chemical Engineering Journal 181-182 (2), 360, 2012.

27. DING L., WU C., DENG H.P., ZHANG X.X. Adsorptive characteristics of phosphate from aqueous solutions by MIEX resin. J Colloid Interf Sci 376 (1), 224, 2012.

28. NEALE P.A., MASTRUP M., BORGMANN T., SCHAFER A.I. Sorption of micropollutant estrone to a water treatment ion exchange resin. J Environ Monitor 12 (1), 311, 2010.

29. BOND T., GOSLAN E.H. PARSONS S.A., JEFFERSON B. Disinfection by-product formation of natural organic matter surrogates and treatment by coagulation, MIEX ${ }^{\circledR}$ and nanofiltration. Water Research 44 (5), 1645, 2010.

30. AHMAD M., LEE S.S., OH S.E., MOHAN D., MOON D.H., LEE Y.H., OK Y.S. Modeling adsorption kinetics of trichloroethylene onto biochars derived from soybean stover and peanut shell wastes. Environ Sci Pollut R 20 (12), 8364, 2013.

31. MAHMOOD T., DIN S.U., NAEEM A., TASLEEM S., ALUM A., MUSTAFA S. Kinetics, equilibrium and thermodynamics studies of arsenate adsorption from aqueous solutions onto iron hydroxide. J Ind Eng Chem 20 (5), 3234, 2014

32. HAMAYUN M., MAHMOOD T., NAEEM A., MUSKA M., DIN S.U., WASEEM M. Equilibrium and kinetics studies of arsenate adsorption by $\mathrm{FePO}_{4}$. Chemosphere 99 (3), 207, 2014.

33. KAYA E.M.O., OZCAN A.S., GOK O., OZCAN A. Adsorption kinetics and isotherm parameters of naphthalene onto natural- and chemically modified bentonite from aqueous solutions. Adsorption 19 (2-4), 879, 2013.

34. KILISLIOGLU A., BILGIN B. Thermodynamic and kinetic investigations of uranium adsorption on amberlite IR-118H resin. Applied Radiation and Isotopes 58 (2), 155, 2003.

35. WANG Z.L., YUE T.L., YUAN Y.H., CAI R., NIU C., GUO C.X. Kinetics of adsorption of bovine serum albumin on magnetic carboxymethyl chitosan nanoparticles. Int J Biol Macromol 58 (7), 57, 2013.

36. ZHOU Q., DUAN Y.F., HONG Y.G., ZHU C., SHE M., ZHANG J., WEI H.Q. Experimental and kinetic studies of gas-phase mercury adsorption by raw and bromine modified activated carbon. Fuel Process Technol 134, 325, 2015.

37. WALKER K.M., BOYER T.H. Long-term performance of bicarbonate-form anion exchange: Removal of dissolved organic matter and bromide from the St. Johns River, FL, USA. Water Research 45 (9), 2875, 2011.

38. TANG Y.L., LIANG S., GUO H.C., YOU H.R., GAO N.Y., YU S.L. Adsorptive characteristics of perchlorate from aqueous solutions by MIEX resin. Colloid Surface A 417 (417), 26, 2013

39. WANG J.H., JI Y.F., DING S.L., MA H.R., HAN X.J. Adsorption and Desorption Behavior of Tannic Acid in Aqueous Solution on Polyaniline Adsorbent. Chinese J Chem Eng 21 (6), 594, 2013.

40. WU F.C., TSENG R.L., JUANG R.S. Characteristics of Elovich equation used for the analysis of adsorption kinetics in dye-chitosan systems. Chemical Engineering Journal 150 (2-3), 366, 2009.

41. HAMEED B.H., TAN I.A. W., AHMAD A.L. Adsorption isotherm, kinetic modeling and mechanism of 2,4,6-trichlorophenol on coconut husk-based activated carbon. Chemical Engineering Journal 144 (2), 235, 2008

42. LIU F.L., GUO Z.B., ZHENG S.R., XU Z.Y. Adsorption of tannic acid and phenol on mesoporous carbon activated by $\mathrm{CO}_{2}$. Chemical Engineering Journal 183 (8), 244, 2012. 
43. ZHOU C.J., WU Q.L., LEI T.Z., NEGULESCU J.I. Adsorption kinetic and equilibrium studies for methylene blue dye by partially hydrolyzed polyacrylamide/ cellulose nanocrystal nanocomposite hydrogels, Chemical Engineering Journal 251 (251), 17, 2014.

44. KUMAR R., BARAKAT M.A., SOLIMAN E.M. Removal of tannic acid from aqueous solution by magnetic carbohydrate natural polymer. J Ind Eng Chem 20 (5), 2992, 2014.

45. MOHAN D., SINGH K.P. Single and multi-component adsorption of cadmium and zinc using activated carbon derived from bagasse - an agricultural waste. Water Research 36 (9), 2304, 2002.

46. DING L., LU X., DENG H.P., ZHANG X.X. Adsorptive Removal of 2,4-Dichlorophenoxyacetic Acid (2,4-D) from Aqueous Solutions Using MIEX Resin. Ind Eng Chem Res 51 (34), 11226, 2012.

47. ZHAO D.L., SHENG G.D., HU J., CHEN C.L., WANG X.K. The adsorption of $\mathrm{Pb}(\mathrm{II})$ on $\mathrm{Mg}_{2} \mathrm{Al}$ layered double hydroxide. Chemical Engineering Journal 171 (1), 167, 2011.

48. DENG Y.H., WANG L., HU X.B., LIU B.Z., WEI Z.B., YANG S.G., SUN C. Highly efficient removal of tannic acid from aqueous solution by chitosan-coated attapulgite. Chemical Engineering Journal 181-182 (1), 300, 2012.
49. VION V.P., VARGHESE S., ANIRUDHAN T.S. Adsorption performance of Zr-pillared montmorillonite for the removal of organic pollutants from aqueous phase. Indian J Chem Techn 10 (2), 201, 2003.

50. VION V., ANIRUDHAN T. Sorption of tannic acid on zirconium pillared clay. J Chem Technol Biot 77 (1), 92, 2001.

51. EL-KAMASH A.M., ZAKI A.A., ELGELEEL M. A. Modeling batch kinetics and thermodynamics of zinc and cadmium ions removal from waste solutions using synthetic zeolite A. J Hazard Mater 127 (1-3), 211, 2005.

52. DEBNATH S., GHOSH U.C. Kinetics, isotherm and thermodynamics for $\mathrm{Cr}(\mathrm{III})$ and $\mathrm{Cr}(\mathrm{VI})$ adsorption from aqueous solutions by crystalline hydrous titanium oxide. The Journal of Chemical Thermodynamics 40 (1), 67, 2008.

53. FOO K.Y., HAMEED B.H. Insights into the modeling of adsorption isotherm systems. Chemical Engineering Journal 156 (1), 2, 2010.

54. ÖZCAN A.S., ERDEM B., ÖZCAN A. Adsorption of Acid Blue 193 from aqueous solutions onto Na-bentonite and DTMA-bentonite. J Colloid Interf Sci 280 (1), 44, 2004.

55. NOLLET H., ROELS M., LUTGEN P., VAN DER MEEREN P., VERSTRAETE W. Removal of PCBs from wastewater using fly ash. Chemosphere 53 (6), 655, 2003. 
